\title{
Comparison of the Microdose Flare Up GnRH Agonist and Antagonist Protocol in Assisted Reproduction with Poor Ovarian Response during Controlled Ovarian Stimulation Cycles
}

\author{
Mohamed Fakhry Elebiary*, Emad Abdelrahman Eltemamy, Abdelmoneim Mohamed Zakaria \\ Department of Obstetrics and Gynecology, Faculty of Medicine, Al-Azhar University, Cairo, Egypt \\ *Corresponding author: Mohamed Fakhry Elebiary, Mobile: (+20) 1002558560, \\ E-Mail: elebiary.mohamed_obs@yahoo.com
}

\begin{abstract}
Background: Poor ovarian response presents a significant challenge in artificial reproductive treatment (ART). Poor responders are estimated to comprise approximately 9- $24 \%$ of IVF cycles patients. Recently, the development of GnRH antagonist protocol offered another approach for ovarian stimulation by blocking the pituitary receptors. There is evidence that application of $\mathrm{GnRH}$ antagonist protocol decreases the duration of ovulatory stimulus and reduce incidence of ovarian hyperstimulation syndrome (OHSS).

Objectives: The aim of the current study was to evaluate the effect of the antagonist protocol to the microdose flare up GnRH agonist protocol for poor ovarian responders undergoing IVF/ICSl treatment.

Patients and Methods: A total of sixty patients of IVF/ICSI assigned to be poor responders were randomized into two groups; group 1 Thirty patients received GnRH antagonist fixed protocol and group 2 thirty patients received a microdose flare up agonist protocol. Patients characteristics and treatment outcomes were statistically compared between groups.

Results: Duration of stimulation was highly significantly lower in the antagonist group than that of the microdose flare up one (antagonist $8.60 \pm 1.63$ versus microdose flare up 12.06 $\pm 2.86 ; \mathrm{p}=0.001$ ). Number of ampoules of HMG was highly significantly lower in the antagonist group than that of the micro dose flare up agonist one (antagonist $23.53 \pm 7.33$ versus micro dose agonist $71.97 \pm 9.35 ; \mathrm{p}=0.001)$. The number of oocytes retrieved in the antagonist group was not different from microdose flare agonist group (5.14 \pm 2.45 vs. $5.11 \pm 1.29 ; \mathrm{p}=0.953)$, and the number of embryos transferred was similar in both groups $(2.03 \pm 0.08$ vs. $2.09 \pm 1.05 ; \mathrm{p}=0.674)$. No significant differences in pregnancy rates were reported.

Conclusion: we offer using the "GnRH antagonist" as a patient friendly protocol in ART with poor ovarian response with Immediate mode of action, similar pregnancy rate, time saving, less duration of stimulation and number of ampoules for stimulation than microdose flare up protocol.
\end{abstract}

Keywords: GnRH antagonist, ovarian hyperstimulation syndrome, poor ovarian response, IVF/ICSI

\section{INTRODUCTION}

Poor ovarian response presents a significant challenge in artificial reproductive treatment (ART). Poor responders are estimated to comprise approximately $9-24 \%$ of IVF cycles patients; however, there is no uniform definition of poor response. Various authors use different definitions of the word, ranging from the number of oocytes retrieved, (ranging from 2 to 5), the maximal E2 level (ranging from 100 to $660 \mathrm{Pg} / \mathrm{ml}$ ) on the day of hCG, the total amount of FSH administered during ovulation and/or cycle cancellation due to poor response to ovarian stimulation when the gonadotrophins starting dose for induction of ovulation was at least 300 IU/day) (1). The management of poor ovarian response is highly controversial. There is no consensus on the optimum controlled ovarian stimulation $(\mathrm{COH})$ protocol in such patients. Increased amount of gonadotrophins and duration of stimulation with possible high cancellation rate have always been a problem in poor responders ${ }^{(2)}$.

A number of randomized controlled trials (RCT) have compared different stimulation protocols; however, none has so far been demonstrated to be superior, such as the addition of growth hormone $(\mathrm{GH})$ or growth hormone releasing hormone (GHRH), transdermal testosterone, aromatase inhibitor, high FSH dose, GnRH agonist stop, GnRH antagonist, $r$ FSH versus $\mathrm{u}$ FSH and the flare up GnRH agonist protocol. None of the treatments could improve the pregnancy rate in poor ovarian responders ${ }^{(3)}$.

The micro dose flare up (MF) protocol has become one of the most common $\mathrm{COH}$ protocols used in poor ovarian responders they showed improved ovarian response and clinical outcomes. The initial release of endogenous gonadotropins induced by low dose GnRH -a with administration of high dose exogenous gonadotropins ${ }^{(4)}$.

GnRH agonists and antagonists are peptides containing 10 amino acids ${ }^{(5)}$. Despite the fact that $\mathrm{GnRH}$ agonist protocol is accompanied by some disadvantages, it has become widely used in clinical IVF- ET treatment, and its application is associated with an increase in the rate of pregnancy ${ }^{(6)}$.

The GnRH antagonists have also been found effective for ovarian gonadotropin release. As a result, the GnRH antagonist protocol has also been widely employed in the clinical settings of women with IVFET poor responders treatment. ${ }^{(7)}$ 
There is evidence that application of $\mathrm{GnRH}$ antagonist protocol decreases the duration of ovulatory stimulus and reduces the incidence of ovarian hyper stimulation syndrome ${ }^{(\mathbf{8})}$.

The aim of the current study was to compare the antagonist protocol to the microdose flare up $\mathrm{GnRH}$ agonist protocol for poor ovarian responders undergoing IVF/ICSI treatment.

\section{PATIENTS AND METHODS}

This prospective randomized controlled study included a total of 60 women who had previous failed IVF attempt due to poor ovarian response to conventional long protocol attending at Obstetrics and Gynecology Clinics, Faculty of Medicine, Al-Azhar University Hospitals. Approval of the ethical committee and a written informed consent from all the subjects were obtained. This study was conducted between January 2017 and December 2017.

Women were randomized according to a computer generated random numeric table. The random allocation sequence was concealed in sealed dark envelopes, then patients were assigned randomly into two groups; group 1; thirty patients received GnRH antagonist fixed protocol and group 2; thirty patients received a microdose flare up agonist protocol. All patients were evaluated before initiation of treatment for their basal day $3 \mathrm{FSH}, \mathrm{LH}$, and E2.

Inclusion criteria: All patients had regular menstrual cycles (27-33 days), BMI less than 30 $\mathrm{Kg} / \mathrm{m} 2$ and one or more failed IVF cycles. There were one to three un-intervened cycles between the last IVF attempt and the current treatment cycle.

Exclusion criteria: Patients with severe endometriosis, history of previous pelvic or ovarian surgery, clinically significant systemic disease, endocrine or metabolic disorders, and severe male factor.

\section{The microdose flare up GnRH agonist protocol:}

Thirty patients had undergone GnRH microdose flare up agonist Protocol, receiving leuprolide acetate (Lucrin 40 mcg SC b.i.d., Abbot, USA) from day 2 of the cycle and continued daily including the day of hCG administration, ovarian stimulation with S.C. highly purified hMG Menopure (Ferring, Denmark) 300 IU daily was commenced from cycle day 3 and until the follicles reach maturity.

\section{Procedures for oocyte retrieval:}

Ovarian response was monitored with frequent serum E2 and serial transvaginal ultrasound examinations then doses of gonadotrophin were adjusted as required in both groups. When 1 to 2 follicles reached a mean diameter of $18 \mathrm{~mm}, \mathrm{HCG}$
(10,000 IU, EMD Serono) had been administered. Oocytes were retrieved under general anesthesia using vaginal ultrasound guided puncture 36-38 hrs. after HCG injection and ICSI were performed for all patients according to the standard procedures as previously reported.

\section{Procedures for embryo transfer:}

Embryo transfer (ET) was carried out 72 hrs. after oocyte retrieval to all patients under ultrasound guidance. Luteal phase support with (Cyclogest 400 mg, ALpharma, England ) once daily started on the day of oocyte retrieval. The cycles were cancelled when E2 showed decreased level or remain plateau in spite increasing the dose of hMG, cycles in which less than 2 mature follicles developed, were either cancelled or converted to intrauterine insemination in patients with patent tube(s). Clinical pregnancy was defined as elevated serum HCG 14 days after ET and the presence of gestational sac(s) by ultrasonography.

\section{Oocyte retrieval:}

Transvaginal ultrasound guided oocyte retrieval was done. Oocyte retrieval was performed in an operating room under general anesthesia 34-36 after HCG injection. The patient was put in the lithotomy position; transvaginal transducer with an attached needle was used. The transducer used had total length $40-50 \mathrm{~cm}$ and a frequency of 5-7 MHz. The transducer put into a finger of a sterile surgical glove. The needle guide should be easy to attach to the transducer when it has been placed in a sterile cover.

The needle used was a sharp needle 18 guage; the surface of needle tip has some kind of preparation that will increase the ultrasound echo, making it easier to identify the position of the needle tip and connected to the suction pump that make a negative pressure of 120 $\mathrm{mmHg}$ which is seems to be optimal for a good retrieval.

With the guiding line of the transducer, the needle was advanced through the vaginal wall into the follicle of the ovary. Once the follicle was entered, suction was gently applied to aspirate the follicular fluid including the oocyte. Then, other follicles were aspirated. Once the ovarian follicles were aspirated on one ovary, the needle was withdrawn, and the procedure repeated on the contralateral ovary.

\section{ICSI procedure:}

ICSI was performed in all cases. ICSI is based on micromanipulation of oocytes and spermatozoa.Fertilization by means of micromanipulation requires denudation of oocytes that is mean removal of the surrounding cumulus and corona cells using a combination of enzymatic and mechanical procedures. This allows precise injection of the oocytes, and assessment of their maturity, which is of critical importance for ICSI. Oocytes may be 
either germinal vesicle (GV), metaphase I (MI), or metaphase II (MIl). GV is recognized by the presence of a typical GV. MI Oocytes are those that have undergone $\mathrm{GV}$ breakdown but not yet extruded the first polar body. MII oocyte displays the presence of a first polar body.

The ICSI procedure was done using an inverted microscope equipped with micromanipulators and micro injectors. The micromanipulators allow three dimensional manipulation of the holding and injection pipette. The microinjectors are used to either fix or release the oocyte with the holding pipette, or to aspirate and inject a spermatozoon

The procedure is carried out in a plastic micro injection dish containing microdroplets covered with mineral oil. The ICSI procedure involves the injection of a single motile spermatozoon into the oocyte. The following steps can be distinguished: (i) A single motile spermatozoon is selected and immobilized by pressing its tail between the microneedle and the bottom of the dish. The sperm cell is then aspirated tail-first into the injection pipette, (ii) Using the holding pipette, the mature oocyte is fixed with the polar body at the 6 o'clock position. The sperm cell is brought to the tip of the injection pipette, (iii) The injection pipette is introduced at the 3 o'clock position and slight suction was done to ensure rupture of the oolemma, (iv) The sperm cell is delivered into the oocyte with a minimal volume of medium. After the procedure, the oocyte was placed into cell culture and checked on the following day for signs of fertilization.

\section{Embryo transfer procedure:}

Grading of a day 3 embryo was based on the number of cells that make up the embryo, the amount of fragmentation, and the symmetry of blastomeres. Fragmentation means parts of an individual cell(s) in the embryo break apart or and appear as small fragments or "blebs" within the embryo. The four level grading systems; Grade A: even cell division, little to no visible fragmentation. Grade B: even cell division, small fragmentation (less than 20\%). Grade C: uneven cell division, moderate fragmentation (30\%-50\%) Grade D: uneven cell division, excessive fragmentation (more than 50\%). Type A, B, and C embryos are eligible for transfer.

Embryo transfer procedure was arranged 48-72 hours after oocyte retrieval. The patient is put in the lithotomy position and the procedure done without anesthesia.The cervix is visualized using Cusco's speculum and cleaned of cervical mucus and vaginal secretions using tissue culture media and sterile gauze. The cervical mucus at the external os is aspirated gently. An embryo transfer catheter was loaded with the embryos and handeled to the clinician. The catheter was inserted through the cervical canal and passed the internal os and then gently advanced in the mid-uterine cavity and stopped from $1-2 \mathrm{~cm}$ short of the fundus, Procedure was done under transabdominal ultrasound guidance as the tin may be carefully guided through the uterine lumen and the fluid droplet containing the embryos is visualized as a very small hypoechoic blip deposited at the tip of the, transfer catheter. After insertion of the catheter, the contents are expelled and the It embryos were deposited. After withdrawal, the catheter was handeled to thes embryologist, who inspects it for retained embryos.

\section{Luteal support:}

All patients received luteal phase support with vaginal progesterone $400 \mathrm{mg}$ (cyclogest) daily starting on the day of oocyte retrieval.

HCG level was measured 14 days after oocyte retrieval. If positive One week later, patient was examined by transvaginal ultrasound to detect gestaional sac.

\section{Outcome measures:}

The main outcome measures were duration of stimulation (in days), consumption of gonadotrophins (in ampoules), cycle cancellation rate, the number of mature follicles, total oocytes retrieved. Secondary outcome measure was the number of embryo transferred, and clinical pregnancy rates were also considered among our observations.

Duration of stimulation was defined as number of days in which HMG was given. Consumption of gonadotrophins was measured as the number of ampoules of HMG consumed by patients, each ampoule contains 75 IU. Cycle cancellation rate represented the number of cancelled cycles to the number of all cycles completed the stimulation. The number of mature follicles was estimated as the number of follicles more than $18 \mathrm{~mm}$ at time of HCG administration by transvaginal ultrasound. Total oocytes retrieved were estimated by the embryologist by examination of follicular fluid under the microscope. Oocytes maturity was observed as well. Number of embryo was estimated by the embryologist as all embryos resulted after ICSI procedure and ready for transfer. Embryo grading was also reported.

Chemical pregnancy was confirmed by serum positive pregnancy test before the appearance of gestational sac on ultrasonography while clinical pregnancy was established when a gestational sac was demonstrated on ultrasonography.

\section{Statistical analysis}

Recorded data were analyzed using the statistical package for social sciences, version 20.0 (SPSS Inc., Chicago, Illinois, USA). Quantitative data were expressed as mean \pm standard deviation (SD). Qualitative data were expressed as frequency and percentage.

\section{The following tests were done:}

- Independent-samples t-test of significance was used when comparing between two means. 
- Chi-square $\left(\mathrm{x}^{2}\right)$ test of significance was used in order to compare proportions between two qualitative parameters.

- The confidence interval was set to $95 \%$ and the margin of error accepted was set to $5 \%$. The p-value was considered significant as the following:

- Probability (P-value)

- P-value $<0.05$ was considered significant.

P-value $<0.001$ was considered as highly significant.

P-value $>0.05$ was considered insignificant.

\section{RESULTS}

Table (1): Total of 60 patients were recruited to the study

\begin{tabular}{|c|c|}
\hline $\begin{array}{c}\text { GnRH Antagonist } \\
30 \text { patients }\end{array}$ & $\begin{array}{c}\text { nnRH micro dose flare } \\
\text { up agonist } \\
\end{array}$ \\
\hline Cycles cancelled & Cycles cancelled \\
2 patients & 1 patient \\
$2 / 30=6.7 \%$ & $1 / 30=3.3 \%$ \\
\hline 28 patients & 29 patients \\
\hline \multicolumn{2}{|c|}{ P value $0.553(\mathrm{NS})$} \\
\hline
\end{tabular}

Table 1 shows total of 60 patients were recruited to the study, GnRH Antagonist include 30 patients, Cycles cancelled in 2 patients and GnRH micro dose flare up agonist include 30 patients, Cycles cancelled in 1 patient.

Table (2): Patients' characteristics in the two groups

\begin{tabular}{|c|c|c|c|}
\hline & $\begin{array}{l}\text { Antagonist } \\
\text { group } \\
\mathrm{N}=28\end{array}$ & $\begin{array}{l}\text { Micro dose } \\
\text { flare up } \\
\text { agonist } \\
\quad \mathrm{N}=29\end{array}$ & $\begin{array}{c}\text { Chi } \\
\text { square test/ } \\
\text { Independent } \\
\text { t test } *\end{array}$ \\
\hline & & & $\mathrm{P}$ value \\
\hline $\begin{array}{l}\text { Age (years) } \\
\text { - Range } \\
\text { - Mean } \pm \text { SD }\end{array}$ & $\begin{array}{c}29-41 \\
34.37 \pm 3 . \\
70\end{array}$ & $\begin{array}{c}28-40 \\
35.6 \pm 3.6 \\
7\end{array}$ & $0.213 *$ \\
\hline BMI (kg/m2) & $25.2 \pm 2.81$ & $25.0 \pm 2.59$ & $0.768 *$ \\
\hline $\begin{array}{l}\text { Duration of } \\
\text { infertility (years) }\end{array}$ & $\begin{array}{l}10.05 \pm \\
5.21\end{array}$ & $11.0 \pm 6.49$ & $0.519 *$ \\
\hline $\begin{array}{c}\text { Type of infertility } \\
\text { (No., \%) } \\
\text { Primary } \\
\text { Secondary }\end{array}$ & \begin{tabular}{|c} 
\\
$23(82.4 \%)$ \\
$5(17.6 \%)$ \\
\end{tabular} & $\begin{array}{c}24(82.8 \%) \\
5(17.2 \%)\end{array}$ & 0.949 \\
\hline
\end{tabular}

Table 2 shows Patients' characteristics in the two groups: There were no statistically significant differences between two groups as regard age; (antagonist 34.3 versus agonist $35.6 ; \mathrm{p}=0.213$ ), body mass index (BMI); (antagonist 25.2 versus agonist 25; $\mathrm{p}=0.768$ ) and duration of infertility; (antagonist group 10.05 versus agonist group $11 ; \mathrm{p}=0.519)$. Most of patients are cases of primary infertility both in the antagonist group (82.4\%) and in agonist group $(82.8 \%)$ with no significant difference $(\mathrm{p}=0.949)$.
Table (3): Basal FSH, LH and E2 in the two groups

\begin{tabular}{|l|c|c|c|}
\hline & $\begin{array}{c}\text { Antagonist } \\
\text { group } \\
\mathrm{N}=28\end{array}$ & $\begin{array}{c}\text { Micro dose } \\
\text { flare up } \\
\text { agonist } \\
\mathrm{N}=29\end{array}$ & $\begin{array}{c}\text { Independent } \\
\text { t test }\end{array}$ \\
\cline { 2 - 4 } & Mean \pm SD & Mean \pm SD & P \\
\hline $\begin{array}{l}\text { Basal FSH } \\
\text { (mIU/ml) }\end{array}$ & $10.31 \pm 2.91$ & $9.97 \pm 2.82$ & 0.655 \\
\hline $\begin{array}{l}\text { Basal LH } \\
\text { (mIU/ml) }\end{array}$ & $7.90 \pm 1.30$ & $8.10 \pm 2.10$ & 0.732 \\
\hline $\begin{array}{l}\text { Basal E2 } \\
\text { (pg/ml })\end{array}$ & $40.83 \pm 6.17$ & $\begin{array}{c}39.37 \pm 7.4 \\
0\end{array}$ & 0.422 \\
\hline
\end{tabular}

Table 3 shows Basal FSH,LH and E2 in the two groups: there was the mean basal FSH in the antagonist arm was 10.31 and in the agonist arm was 9.97 with no statistically significant difference $(\mathrm{p}=0.655)$, the mean basal LH in the antagonist arm was 7.90 and in the agonist arm was 8.10 with no statistically significant difference $(p=0.732)$ and the mean basal E2 in the antagonist arm was 40.83 and in the agonist arm was 39.37 with no statistically significant difference $(\mathrm{p}=0.422)$.

Table (4): Endometrial thickness in the two groups

\begin{tabular}{|c|c|c|c|}
\hline & $\begin{array}{c}\text { Antagonist } \\
\text { group } \\
\mathrm{N}=28\end{array}$ & $\begin{array}{c}\text { Micro dose } \\
\text { flare up agonist } \\
\mathrm{N}=29\end{array}$ & $\begin{array}{c}\text { Independent } \\
\text { t test }\end{array}$ \\
\cline { 2 - 4 } & Mean & Mean \pm SD & $\mathrm{P}$ \\
\hline $\begin{array}{c}\text { Endometrial } \\
\text { thickness } \\
(\mathrm{mm})\end{array}$ & $0.92 \pm 2.31$ & $11.30 \pm 1.90$ & 0.499 \\
\hline
\end{tabular}

Table 4 shows Endometrial thickness in the two groups: There were no statistically significant differences between two groups as regard endometrial thickness (antagonist was $10.92 \pm 2.31$ and agonist was $11.30 \pm 1.90 ; \mathrm{p}=0.499)$.

Table (5): Duration of stimulation and number of HMG ampoules in the two groups

\begin{tabular}{|c|c|c|c|}
\hline & $\begin{array}{c}\text { Antagonist } \\
\text { group } \\
\mathrm{N}=28\end{array}$ & $\begin{array}{c}\text { Micro dose } \\
\text { flare up agonist } \\
\mathrm{N}=29\end{array}$ & $\begin{array}{c}\text { Independent } \\
\text { t test }\end{array}$ \\
\cline { 2 - 4 } & Mean & Mean \pm SD & $\mathrm{P}$ \\
\hline $\begin{array}{c}\text { Duration of } \\
\text { stimulation } \\
\text { (days) }\end{array}$ & $\begin{array}{c}8.60 \pm \\
1.63\end{array}$ & $12.06 \pm 2.86$ & 0.001 \\
\hline $\begin{array}{c}\text { Number of } \\
\text { ampoules of } \\
\text { HMG }\end{array}$ & $\begin{array}{c}23.53 \pm \\
7.33\end{array}$ & $71.97 \pm 9.35$ & 0.001 \\
\hline
\end{tabular}

Table 5 shows Duration of stimulation and number of HMG ampoules in the two groups: Duration of 
stimulation was highly significantly lower in the antagonist group than that of the agonist one (antagonist $8.60 \pm 1.63$ versus agonist $12.06 \pm 2.86$; $\mathrm{p}=0.001$ ). Number of ampoules of HMG was highly significantly lower in the antagonist group than that of the agonist one (antagonist $23.53 \pm 7.33$ versus agonist 71.97 $\pm 9.35 ; \mathrm{p}=0.001)$.

Table (6): E2 day HCG in the two groups

\begin{tabular}{|c|c|c|c|}
\hline & $\begin{array}{c}\text { Antagonist } \\
\text { group } \\
\mathrm{N}=28\end{array}$ & $\begin{array}{c}\text { Micro dose } \\
\text { flare up agonist } \\
\mathrm{N}=29\end{array}$ & $\begin{array}{c}\text { Independ } \\
\text { nt t test }\end{array}$ \\
\cline { 2 - 4 } & Mean \pm SD & Mean \pm SD & $\mathrm{P}$ \\
\hline $\begin{array}{c}\mathrm{E} 2 \text { day HCG } \\
(\mathrm{pg} / \mathrm{ml})\end{array}$ & $\begin{array}{c}998.87 \pm \\
22.43\end{array}$ & $\begin{array}{c}1039.07 \pm \\
89.91\end{array}$ & 0.465 \\
\hline
\end{tabular}

Table 6 shows E2 day HCG in the two groups: E2 day HCG was not significant in the antagonist group as agoinst group (antagonist $998.87 \pm 222.43$ versus agonist $1039.07 \pm 189.91 ; \mathrm{p}=0.465$ ).

Table (7): Number of mature oocytes in the two groups

\begin{tabular}{|c|c|c|c|}
\hline & $\begin{array}{c}\text { Antagonist } \\
\text { group } \\
\mathrm{N}=28\end{array}$ & $\begin{array}{c}\text { Micro dose } \\
\text { flare up } \\
\text { agonist } \\
\mathrm{N}=29\end{array}$ & $\begin{array}{c}\text { Independent } \\
\text { t test }\end{array}$ \\
\cline { 2 - 4 } & Mean $\pm \mathrm{SD}$ & $\begin{array}{c}\text { Mean } \\
\pm \mathrm{SD}\end{array}$ & $\mathrm{P}$ \\
\hline $\begin{array}{c}\text { Number } \\
\text { of mature } \\
\text { oocytes }\end{array}$ & $5.1 \pm 1.54$ & $\begin{array}{c}5.11 \pm \\
1.29\end{array}$ & 0.953 \\
\hline
\end{tabular}

Table 7 shows Number of mature oocytes in the two groups: Number of mature oocytes was not significant in the antagonist group as agoinst group (antagonist $5.1 \pm 2.54$ versus agonist $5.11 \pm 1.29$; $\mathrm{p}=0.953)$.

Table (8): Number of oocytes retrieved in the two groups

\begin{tabular}{|c|c|c|c|}
\hline & $\begin{array}{c}\text { Antagonist } \\
\text { group } \\
\mathrm{N}=28\end{array}$ & $\begin{array}{c}\text { Micro dose } \\
\text { flare up agonist } \\
\mathrm{N}=29\end{array}$ & $\begin{array}{c}\text { Independent } \\
\text { t test }\end{array}$ \\
\cline { 2 - 4 } & Mean \pm SD & Mean \pm SD & $\mathrm{P}$ \\
\hline $\begin{array}{c}\text { Total } \\
\text { number of } \\
\text { Oocytes }\end{array}$ & $5.14 \pm 2.45$ & $5.11 \pm 1.29$ & 0.953 \\
\hline $\begin{array}{c}\text { Number } \\
\text { of GV } \\
\text { Oocytes }\end{array}$ & $1.29 \pm 0.9$ & $1.32 \pm 0.73$ & 0.890 \\
\hline $\begin{array}{c}\text { Number } \\
\text { of MI } \\
\text { Oocytes }\end{array}$ & $1.23 \pm 0.52$ & $1.15 \pm 0.62$ & 0.600 \\
\hline $\begin{array}{c}\text { Number } \\
\text { of MII } \\
\text { Oocytes }\end{array}$ & $2.62 \pm 1.11$ & $2.64 \pm 0.80$ & 0.937 \\
\hline
\end{tabular}

Table 8 shows Number of oocytes retrieved in the two groups: No statistically significant difference $(\mathrm{p}=0.953)$ was detected in the total number of oocytes in the two groups (antagonist $5.14 \pm 2.45$ versus agonist $5.11 \pm 1.29$ ). The same results were obtained during analysis of number of oocytes MI, oocytes MII, and germinal vesicles $(\mathrm{GV})$ in the two groups.

Table (9): Number of fertilized oocytes in the two groups

\begin{tabular}{|l|c|c|c|}
\hline & $\begin{array}{c}\text { Antagonist } \\
\text { group } \\
\mathrm{N}=28\end{array}$ & $\begin{array}{c}\text { Micro dose } \\
\text { flare up agonist } \\
\mathrm{N}=29\end{array}$ & $\begin{array}{c}\text { Independent } \\
\mathrm{t} \text { test }\end{array}$ \\
\cline { 2 - 4 } & Mean $\pm \mathrm{SD}$ & Mean $\pm \mathrm{SD}$ & $\mathrm{P}$ \\
\hline $\begin{array}{l}\text { Number of } \\
\begin{array}{l}\text { Fertilized } \\
\text { Oocytes }\end{array}\end{array}$ & $3.31 \pm 1.35$ & $3.52 \pm 1.01$ & 0.507 \\
\hline
\end{tabular}

Table 9 shows Number of fertilized oocytes in the two groups: There was no statistically significant difference $(\mathrm{p}=0.507)$ in number of fertilized oocytes between the two groups (antagonist group 3.31 versus Agonist group 3.52)

Table (10): Number of embryos transferred and their grades in the two groups

\begin{tabular}{|c|c|c|c|}
\hline & $\begin{array}{c}\text { Antagonist } \\
\text { group } \\
\mathrm{N}=28\end{array}$ & $\begin{array}{c}\text { Micro dose } \\
\text { flare up } \\
\text { agonist N=29 }\end{array}$ & $\begin{array}{c}\text { Independe } \\
\text { t test }\end{array}$ \\
\cline { 2 - 4 } & Mean \pm SD & Mean \pm SD & $\mathrm{P}$ \\
\hline $\begin{array}{c}\text { Total } \\
\text { number } \\
\text { Embryos } \\
\text { transferred }\end{array}$ & $2.03 \pm 0.08$ & $2.09 \pm 1.05$ & 0.764 \\
$\begin{array}{c}\text { Grade A } \\
\text { Embryos } \\
\text { transferred }\end{array}$ & $1.227 \pm 0.813$ & $1.259 \pm 0.685$ & 0.884 \\
\hline $\begin{array}{c}\text { Grade B } \\
\text { Embryos } \\
\text { transferred }\end{array}$ & $0.401 \pm 0.608$ & $0.436 \pm 0.351$ & 0.790 \\
\hline $\begin{array}{c}\text { Grade C } \\
\text { Embryos } \\
\text { transferred }\end{array}$ & $0.400 \pm 0.541$ & $0.391 \pm 0.394$ & 0.942 \\
\hline
\end{tabular}

Table 10 shows Number of embryos transferred and their grades in the two groups: There was no statistically significant difference $(p=0.764)$ in the number of embryos transferred in the two groups (antagonist group $2.03 \pm 0.08$ versus 2.09 \pm 1.05 agonist group). No statistically significant difference was detected in grade A embryos in the two groups (antagonist group $1.22 \pm 0.81$ versus $1.25 \pm 0.68$ agonist group; $\mathrm{p}=0.88$ ). The same results were obtained with grades $\mathrm{B}$ and $\mathrm{C}$ embryos. 
Table (7): Pregnancy rates in both groups

\begin{tabular}{|r|c|c|c|c|c|}
\hline & \multicolumn{2}{|c|}{$\begin{array}{c}\text { Antagonist } \\
\text { group } \\
\text { N=28 }\end{array}$} & \multicolumn{2}{|c|}{$\begin{array}{r}\text { Micro dose } \\
\text { flare up agonist } \\
\text { N=29 }\end{array}$} & $\begin{array}{c}\text { Chi } \\
\text { square } \\
\text { test }\end{array}$ \\
\cline { 2 - 6 } & No & $\%$ & No & $\%$ & $\mathrm{P}$ \\
\hline $\begin{array}{c}\text { Clinical } \\
\text { pregnancy rate } \\
\text { per cycle }\end{array}$ & 4 & $14.3 \%$ & 5 & $17.2 \%$ & 0.759 \\
\hline
\end{tabular}

Table 11 shows Pregnancy rates in both groups: There were no statistically significant differences between the two groups in clinical pregnancy rate per cycle (antagonist $14.3 \%$ versus gonist $17.2 \%$; $\mathrm{p}=0.759$ ).

\section{DISCUSSION}

Dominguez-Rodriguez et al. (9) reported that GnRH-ang protocols resulted in significantly lower duration of stimulation compared to GnRH-a protocols in POR; however, CCR and CPR were similar between the groups. In our study, duration of stimulation was highly significantly lower in the antagonist group than that of the agonist one (antagonist 8.60 \pm 1.63 versus agonist 12.06 \pm 2.86 ; $\mathrm{p}=0.001$ ). Number of ampoules of HMG was highly significantly lower in the antagonist group than that of the agonist one (antagonist $23.53 \pm 7.33$ versus agonist 71.97 $\pm 9.35 ; \mathrm{p}=0.001)$.

Our study included 60 patients who received either the GnRH-a flare or the GnRH-ant protocol. The similarity in the baseline characteristics of the groups can make it possible to compare the outcomes. The results of our study appear to confirm the conclusion of some already published reviews indicating less days of stimulation and less ampoules of stimulationin $\mathrm{GnRH}$-antagonist cycles compared with GnRH-microdose cycles $(10,11)$ with similar CPR ${ }^{(11,12,13)}$. Nevertheless, additional RCT with better planning and larger sample size are still needed to further confirm these results.

Cheung et al. (2) published the first prospective, randomized, controlled trial comparing a fixed, multi-dose GnRH antagonist protocol with a standard long GnRH agonist protocol in poor responders. Unfortunately, this study failed to demonstrate an overall improvement in ovarian responsiveness. The authors suggested that clinical outcomes may be improved by developing flexible antagonist regimens, The aim of our trial was to compare fixed multi-dose GnRH antagonist protocol with a microdose flare up $\mathrm{GnRH}$ agonist protocol in poor responders.

Marti et al. (10), Tazegiil et al. (11) and Tehraninejad et al. ${ }^{(12)}$, conducted three prospective randomized trials comparing the flexible multidose antagonist protocol versus a microdose GnRH-agonist long protocol. These trial designs were similar to ours.
Marti et al. ${ }^{(10)}$ added $\mathrm{E} 2<600 \mathrm{pg} / \mathrm{mL}$ on the day of HCG administration using a previous long $\mathrm{GnRH}$ agonist protocol as the criterion for patient selection. The same was done by Tazegiil $\boldsymbol{e t} \boldsymbol{a l}$. (11) and Tehraninejad et al. (12), except for using E2 $<500 \mathrm{Pg} / \mathrm{ml}$ on the day of HCG. We also included those with repeated high basal levels of FSH around $10 \mathrm{mlU} / \mathrm{ml}$. Despite being less sensitive and specific, we relied upon FSH evaluation for ovarian reserve because it is available and less expensive. Maternal age alone had not been considered as a criterion for selection of poor responders in our trial. The same was used by Tazegiil et al. (10), but threshold level of FSH was > 13 $\mathrm{mlU} / \mathrm{ml}$. Tehraninejad et $\boldsymbol{a l} .^{\left({ }^{(12)}\right.}$ but threshold level of FSH was $>15 \mathrm{mlU} / \mathrm{ml}$. On the contrary Marti et $\boldsymbol{a l} .{ }^{(10)}$ did not use any prospective criteria.

The significant reduction of number of ampoules of gonadotrophins in antagonist group when compared to the microdose flare group $(23.53 \pm 7.33$ vs $71.97 \pm 9.35 ; \mathrm{p}=0.001$ ) found in our study could be explained by the absence of deep pituitary suppression of GnRHa and this is the code of using different methods for pituitary suppression like GnJRH antagonist. This came in agreement with Marti et al. (10), Tehraninejad et al. ${ }^{(12)}$. In contrast, number of consumed ampoules of gonadotrophins was similar between both groups according to Tehraninejad et $\boldsymbol{a l} .^{(12)}$, there was a decrease in the duration of ovarian stimulation in the antagonist group in comparison with microdose flare up group in our study and this decrease was significant $(8.60 \pm$ 1.63 vs $12.06 \pm 2.86 ; p=0.001)$. This finding was not expected when using GnRH antagonist in poor responders but it was also noticed by Tehraninejad et al. ${ }^{(12)}$. However, Marti et al. (10), Tazegiil et al. (11) showed significantly reduction in the duration in the antagonist group.

The number of oocytes retrieved for both groups was similar in our study in antagonist versus in microdose flare up $(5.14 \pm 2.45$ vs $5.11 \pm 1.29$; $\mathrm{p}=0.953$ ). This was similarly reported by Tazegiil et al. ${ }^{(11)}$ and Tehraninejad et al. ${ }^{(12)}$, on the other hand, Marti et al. (10), found that the number of oocytes retrieved was significantly higher in the antagonist than in the agonist groups. Nevertheless, the number of embryos transferred of both groups was similar in the antagonist versus microdose ( $2.03 \pm 0.08$ VS $2.09 \pm 1.05 ; \mathrm{p}=0.764)$ in our study as well as in the three trials.

We reported cancellation rates in both groups; $3.3 \%$ in the microdose group and $6.7 \%$ in the antagonist one; $\mathrm{P}=0.553$. In comparison, Tazegiil et al. (11) showed cancellation rate $6.6 \%$ in the agonist group and $9 \%$ in the antagonist one. Tehraninejad et $\boldsymbol{a l} .{ }^{(12)}$, showed no cancelled cycles with the use of agonist protocol and only one cycle with the use of the antagonist one. 
To sum up, this trial did not show significant different in pregnancy rates between the microdose flare up and antagonist protocols. However, the patients would get benefit from the reduced amount of gonadotropins and duration of stimulation upon using GnRH antagonist. We can recommend the antagonist protocol for most of poor ovarian responders.

\section{CONCLUSION}

It could be concluded that a protocol including $\mathrm{GnRH}$ antagonist appears at least as effective as one using a GnRH microdose flare up agonist in patients with poor ovarian response undergoing ICSI. On the basis of these results, we offer using the "GnRH antagonist" as a patient friendly protocol in ART with poor ovarian response with Immediate mode of action, similar pregnancy rate, time saving, less duration of stimulation and number of ampoules for stimulation than microdose flare up protocol. However, more (larger) randomized controlled trials for statistical analysis are required to optimally compare $\mathrm{GnRH}$ microdose flare up agonists and antagonists for their use in IVF or ICSI therapy in poor responders.

\section{RECOMMENDATIONS}

The land is still virgin and more well-designed trials are required for illustrating the proper management of poor ovarian responders. Many topics are still in need to be appropriately investigated. Bigger multicenter study comprising large number of cases recruited according to the recent Bologna criteria to compare between microdose flare up agonist and fixed early antagonist protocol. The role of adjuvant such as growth hormone should be scrutinized in well-designed trials. Simple minimal stimulation protocols should be revisited as well in properly designed trials.

\section{REFERENCES}

1- Huirne J A, Homhurg $R$ and Lamhalk CIL (2007): Are GnRH antagonists comparable to agonists for use in IVF? Hum Reprod., 22:2805-2813.

2- Cheung LP, Lam PM, Lok IH et al. (2005): GnRH antagonist versus long GnRH agonist protocol in poor responders undergoing IVF: a randomized controlled trial. Hum Reprod., 20 (3):616-21.
3- Sbracia M, Colahianchi J, Giallonardo A et al. (2009): Cetrorelix protocol versus gonadotropinreleasing hormone analog suppression long protocol for superovulation in intracytoplasmic sperm injection patients older than 40. Fertil Steril., 91:1842-1847.

4- Olivennes F, Belaisch-Allart J, Emperaire JC et al. (2000): Prospective, randomized, controlled study of in vitro fertilization-embryo transfer with a single dose of a luteinizing hormone-releasing hormone (LFI-RH) antagonist (cetrorelix) or a depot formula of an LH-RPI agonist (triptorelin). Fertil Steril., 73:314-320.

5- Itskovitz-Eldor J, Koi S, Mannaerts B et al. (2000): Use of a single bolus of GnRH agonist triptorelin to trigger ovulation after $\mathrm{GnRH}$ antagonist ganirelix treatment in women undergoing ovarian stimulation for assisted reproduction, with special reference to the prevention of ovarian hyperstimulation syndrome: preliminary report: short communication. Hum Reprod., 15:1965-1968.

6- Griesinger G, Felberbaum RE, Schultze-Mosgau A et al. (2004): Gonadotropin-releasing hormone antagonists for assisted reproductive techniques: are there clinical differences between agents? Drugs, 64:563-575.

7- Bodri D, Sankara SK and Coomarasamy A (2011): Gonadotropin-releasing hormone agonists versus antagonists for controlled ovarian hyperstimulation in oocyte donors: a systematic review and meta-analysis. Fertil Steril., 95:164-169.

8- Cota AM, Oliveira JB, Petersen CG et al. (2012): GnRH agonist versus GnRH antagonist in assisted reproduction cycles: oocyte morphology. Reprod Biol Endocrinol., 10:33-36.

9- Dominguez-Rodriguez A, Abreu-Gonzalez $P$ and Reiter RJ (2014): The potential usefulness of serum melatonin level to predict heart failure in patients with hypertensive cardiomyopathy. International Journal of Cardiology, 174(2):415-7.

10- Marti R, Caserta D, Dolo V et al. (2005): GnRH antagonist in IVF poor-responder patients: results of a randomized trial. Reprod Biomed Online, 11 (2): 189-93.

11- Tazegiii A, Grkemli H, Ozdemir S et al. (2008): Comparison of multiple dose GnRH antagonist and minidose long agonist protocols in poor responders undergoing in vitro fertilization: a randomized controlled trial. Arch Gynecol Obstet., 278(5): 467-72.

12- Tehraninejad ES, Fazel A, Samiei A et al. (2009): Flexible multi-dose GnRH antagonist versus long GnRH agonist protocol in poor responders: A randomized controlled trial. Int J Fertil Steril., 4(8): 1619. 